\title{
A PROPRIEDADE RURAL NOS DEBATES DA ASSEMBLEIA NACIONAL CONSTITUINTE
}

\section{THE RURAL PROPERTY IN THE DEBATES OF THE CONSTITUENT NATIONAL ASSEMBLY}

\section{João Daniel Macedo Sá1}

\section{Resumo}

O presente trabalho procura refletir sobre o processo constitucional brasileiro. Para tanto, se propõe a analisar a proteção da propriedade rural a partir dos debates da Assembleia Nacional Constituinte, que antecederam e delinearam os contornos da Constituição Federal de 1988. Desse modo, procura identificar em que medida, e sob qual contexto político, foi desenhada a fundamentação da proteção conferida à propriedade rural. Ao final, apresenta uma crítica ao resultado do processo legislativo e defende a necessidade de pensar os objetivos das políticas públicas no espaço agrário sob um novo enfoque constitucional, que traduza uma atuação mais eficiente do poder público.

Palavras-chave: Assembleia Nacional Constituinte; Propriedade Rural; Constituição Federal de 1988.

\begin{abstract}
The present work seeks to reflect about the Brazilian constitutional process. In order to do so, starting from the debates of the National Constituent Assembly, it intends to analyze the protection of rural property. This process preceded and delineated the contours of the Federal Constitution of 1988. In this way, it seeks to identify to what extent, and under which political context, was drawn the basis of the protection afforded to rural property. In conclusion, it presents a critique about the outcome of the legislative process and advocates the necessity to think about public policy under a new constitutional approach, in a more efficient way.
\end{abstract}

Keywords: National Constituent Assembly; Rural property; Federal Constitution of 1988.

\footnotetext{
${ }^{1}$ Doutor em Direito. Professor Adjunto da Universidade Federal do Pará. Advogado e consultor jurídico.
} 


\section{INTRODUÇÃO}

Ainda hoje, transcorridos 29 anos da promulgação da CF/88, discute-se qual é o papel da propriedade rural no desenvolvimento do país. A terra está intimamente ligada a subsistência do homem, e é na sua distribuição e acesso que se reconhece uma das expressões da desigualdade social existente na sociedade brasileira.

A esse respeito, Piketty (2014, p. 46) lembra que, historicamente, a tensão entre proprietário e camponês, entre aquele que possui a terra e aquele que a cultiva, entre o que recebe os lucros e o que os possibilita, está no cerne da desigualdade social, e de todas as revoltas e rebeliões, das sociedades tradicionais.

Por isso, torna-se importante analisar e entender em que medida, e sob qual contexto político, foi desenhada a fundamentação da proteção conferida à propriedade rural na, ainda vigente, Constituição Brasileira, promulgada em 1988.

Historicamente, e do ponto de vista constitucional, o condicionamento da propriedade ao cumprimento de uma função social teve seu início no Brasil, em 1934, quando o exercício do direito de propriedade passou expressamente a ser limitado pelo interesse social (ou coletivo), caracterizando gradativa mudança de enfoque na preponderância do interesse público sobre o particular ${ }^{2}$.

Ao nos propormos a fazer uma análise a partir dos debates da Assembleia Nacional Constituinte (ANC), nosso objetivo foi tentar entender o contexto em que foram promulgados os artigos que tratam da função social da propriedade rural $^{3}$, tendo como pressuposto o fato de que a norma reproduz a ideologia e as contradições das visões de mundo dos diferentes grupos daquela época.

O resgate dos principais fatos, questões e a linha cronológica dos debates travados ao longo da Assembleia Nacional Constituinte estão apoiados na obra "Buraco negro: a reforma agrária na Constituinte de 1987-88”, de José Gomes da Silva (SILVA, 1989).

\footnotetext{
${ }^{2}$ Pode-se dizer que o direito de propriedade originariamente é materializado como um direito do indivíduo frente ao Estado, sendo por isso apresentado como um direito de cunho negativo, que impunha deveres de abstenção. Segundo Sarlet (2015), o núcleo material das primeiras constituições de matriz liberal-burguesa era composto pela noção de limitação jurídica do poder estatal, pelo princípio da separação dos poderes e pela garantia de alguns direitos fundamentais.

${ }^{3}$ A noção de função social já havia sido lançada desde o século XVIII, em meio aos movimentos contra o individualismo exacerbado do direito privado. O movimento de funcionalização do direito (também denominado de coletivismo) propôs a compreensão do direito privado em função das suas finalidades sociais e econômicas, defendendo o sacrifício da dogmática própria das relações privadas, estruturalmente centrada na manutenção da igual liberdade, em função do interesse social (DRESCH, 2013).
} 
A metodologia do trabalho baseou-se em pesquisa teórica, com levantamento bibliográfico. Para justificar e argumentar sobre as hipóteses levantadas será utilizado o método dedutivo, por nos parecer o mais adequado a essa pesquisa ${ }^{4}$.

O trabalho se desenvolve em três capítulos, sendo o capítulo 2 dedicado ao momento que antecede os debates ocorridos durante a Constituinte. No capítulo 3 são apresentadas questões ligadas ao tema da propriedade rural nos debates da Constituinte, com especial destaque para a desapropriação para fins de reforma agrária e o problema da produtividade, e a atuação do chamado Centrão. O capítulo 4 sintetiza as principais críticas e observações ao texto constitucional aprovado.

\section{A ASSEMBLEIA NACIONAL CONSTITUINTE: CONTEXTO HISTÓRICO}

No período de 1964 a 1985 o Brasil encontrava-se em um contexto em que os direitos e garantias fundamentais haviam sido deixados de lado e um Estado autoritário havia se instaurado. A necessidade de uma nova constituição era premente.

A partir do fim da ditadura militar, que encerra seu ciclo com a eleição indireta de Tancredo Neves, sucedido após sua morte pelo vice-presidente José Sarney, o desenho de uma Constituinte foi sendo construído. Segundo Rattes (2009, p. 25), “após o movimento 'Diretas Já', com a solução Tancredo-Sarney, surgiu o compromisso de convocação de uma Constituinte, que, mesmo Congressual, trouxesse no Ato Convocatório, a afirmação do seu poder livre e soberano".

Para formular uma nova constituição para o país, cumprindo uma das promessas de campanha da Aliança Democrática, o então presidente José Sarney deu início aos debates sobre a convocação da ANC, que apesar das divergências ${ }^{5}$, acabou se estabelecendo a partir da transformação do Congresso Nacional a ser eleito em 1986, em Assembleia Constituinte.

Assim, em 15 de novembro de 1986, foram realizadas eleições diretas para deputados e senadores que formariam a ANC, que foi instalada oficialmente em 01 de fevereiro de 1987. O

\footnotetext{
${ }^{4} \mathrm{O}$ método dedutivo baseia-se num "procedimento lógico, raciocínio pelo qual se pode tirar de uma ou de várias proposições (premissas) uma conclusão que delas decorre por força puramente lógica. A conclusão segue-se necessariamente das premissas" (SEVERINO, 2007, p.105).

${ }^{5}$ Alguns setores defendiam a convocação de uma Constituinte exclusiva, desvinculada do Congresso Nacional, argumentando que os responsáveis pela elaboração da nova Carta Magna teriam mais legitimidade e independência para realizar seus trabalhos se fossem escolhidos estritamente para essa função.
} 
Deputado Ulysses Guimarães, do PMDB de São Paulo, foi eleito no dia 02 de fevereiro de 1987, para a presidência da ANC.

No período que antecedeu a ANC os cidadãos foram convidados a apresentar sugestões à futura Carta perante a Comissão de Estudos Constitucionais, e perante o Senado Federal, por meio de um programa específico.

O Regimento Interno da ANC foi promulgado em 24 de março de 1987, e previu a criação de 8 Comissões Temáticas, compostas por 63 membros titulares e igual número de suplentes, sendo cada uma dividida em 3 Subcomissões, num total de 24. Além das Comissões Temáticas, foi criada uma Comissão de Sistematização ${ }^{6}$.

Instalada a Assembléia Nacional Constituinte, seu regimento interno possibilitou a apresentação de 'sugestões' de legislativos, tribunais e entidades associativas. A Presidência não foi rígida e aceitou idéias oriundas de qualquer cidadão, governador ou prefeito, categorias não incluídas expressamente no dispositivo de permissão. Eram oito Comissões Temáticas e vinte e quatro Subcomissões, onde havia a possibilidade de apresentação oral das proposições perante o plenário. Foram 11.989 sugestões canalizadas para as Subcomissões, enviadas pelos constituintes e pela sociedade civil (RATTES, 2009, p. 26).

A Comissão de Sistematização foi presidida por Afonso Arinos e teve, como relator Bernardo Cabral (que posteriormente também assumiu a função de relator geral da ANC), sendo responsável pela consolidação dos 7 anteprojetos apresentados pelas Comissões Temáticas.

O primeiro anteprojeto de Constituição apresentado por Bernardo Cabral continha 501 artigos distribuídos em 10 títulos, e sofreu 5.624 emendas dos constituintes e dos cidadãos.

O processo Constituinte contou com a participação da sociedade civil e de diversas entidades ligadas aos movimentos sociais, gerando amplos debates sobre temas polêmicos, dentre os quais, a questão da propriedade rural.

\section{A PROPRIEDADE RURAL NA CONSTITUINTE}

O tema relativo à propriedade rural ganhou destaque na ANC em razão dos debates acerca da estrutura fundiária do país e da demanda por uma melhor distribuição e destinação das terras. Também se discutia acerca da especulação sobre terras improdutivas, da necessidade

\footnotetext{
6 Disponível em: <http://www2.camara.leg.br/atividade-legislativa/legislacao/Constituicoes_Brasileiras / constituicao-cidada/assembleia-nacional-constituinte/fundo-assembleia-nacional-constituinte/saiba-mais...-2.2historia-administrativa> Acesso em: 17/05/2017.
} 


\section{A PROPRIEDADE RURAL NOS DEBATES DA ASSEMBLEIA NACIONAL CONSTITUINTE}

de estruturação de uma política agrícola, da proteção da pequena propriedade e principalmente sobre a reforma agrária.

Nesse aspecto, o foco principal dos debates tratava de questões ligadas ao conceito de propriedade produtiva, à possibilidade de imediata imissão de posse, e à fixação do preço e do prévio pagamento dos imóveis que seriam desapropriados por interesse social.

O tema, considerado de grande relevância, provocou inclusive uma maior articulação entre diversos grupos mobilizados em torno da Campanha Nacional pela Reforma Agrária (CNRA). A CNRA havia sido criada em abril de 1983 por 6 entidades, a Associação Brasileira de Reforma Agraria (ABRA), Conselho Indigenista Missionário (CIMI), Confederação Nacional dos Trabalhadores na Agricultura (CONTAG), Comissão Pastoral da Terra (CPT), Instituto Brasileiro de Análises Sociais e Econômicas (IBASE) e a Confederação Nacional dos Bispos do Brasil (CNBB), e posteriormente foi apoiada por outros grupos ligados aos movimentos sociais ${ }^{7}$.

Segundo Silva (1989, p. 171), duas questões fundamentais sobre o direito de propriedade decorriam do texto da própria Constituição de 1969: a primeira versava sobre a garantia expressa do direito de propriedade, e a segunda referia-se à possibilidade de desapropriação por interesse social ou necessidade/utilidade pública.

O Projeto de Sistematização da Comissão havia explicitado os mesmos aspectos já definidos pela Constituição anterior. Desse modo, em vez da garantia do direito de propriedade, era a própria propriedade que vinha a ser protegida pelo Estado.

Com a apresentação do Anteprojeto, o Regimento Interno possibilitava que os eleitores (desde que atingido o número de trinta mil assinaturas) pudessem subscrever propostas organizadas sob a responsabilidade de, pelo menos, três entidades associativas.

Percebe-se que a questão da propriedade rural foi tema importante para o processo da ANC, pois recebeu imensa participação popular, tendo sido objeto de 6 das 122 emendas

\footnotetext{
${ }^{7}$ Disponível em: http://base.d-p-h.info/pt/fiches/premierdph/fiche-premierdph-278.html Acesso em: 19 nov 2014.
} 
populares $^{8}$ apresentadas, somando-se quase um milhão e quinhentas mil assinaturas ${ }^{9}$ (BRASIL, 1988).

Como se verifica, as discussões acerca do tema da propriedade e da reforma agrária no processo Constituinte, tanto antecedem como marcam toda a fase de promulgação da nova Constituição brasileira.

Em uma publicação de maio de 1986, o Centro Ecumênico de Documentação e Informação trouxe uma separata com o tema "A questão agrária e a constituinte", propondo, no final do texto, questões como: Que normas constitucionais deveriam reger a propriedade e a utilização das terras agrícolas no Brasil? Em que casos o poder público deveria promover desapropriações, e como deveriam ser efetuadas as indenizações? Deveriam existir casos de expropriação de terras sem indenização aos proprietários? Deveriam ser fixados limites máximos de propriedade rurais privadas? (CALDEIRA, 1986).

Ampliando a discussão, Comparato (1986) também chegou a propor um anteprojeto de Constituição em que defendia que a propriedade representava uma das garantias de proteção da dignidade humana. Afirmava que:

1) a propriedade, enquanto garantia de proteção à pessoa humana, não pode ser suprimida ou sacrificada aos interesses sociais, porque a dignidade da pessoa humana é o primeiro e mais fundamental valor social;

2) nas hipóteses em que ela não é condição da dignidade da pessoa humana, a propriedade privada deve ceder o passo à realização dos interesses sociais, com indenização limitada ou mesmo sem indenização alguma no caso de concentração abusiva.

O fato é que o amplo debate democrático instalado com o processo Constituinte provocou uma reação da ala mais conservadora ${ }^{10}$ dos Congressistas eleitos em 1986,

\footnotetext{
${ }^{8}$ É interessante olhar, especificamente, para a Emenda Popular n ${ }^{\circ}$ PE00052-1, da CONTAG, ABRA e CPT, que, em resumo: possibilitava a perda sumária dos imóveis inexplorados $\left(\right.$ art. $\left.1^{\circ}, \S 1^{\circ}\right)$; previa a imissão automática na posse dos imóveis rurais desapropriados por interesse social para fins de reforma agrária (art. $2^{\circ}, \S 2^{\circ}$ ); substituía o termo função social do Estatuto da Terra pelo princípio da obrigação social (art. $1^{\circ}$, caput); incluía outros parâmetros para caracterização da obrigação social $\left(\right.$ Art. $\left.1^{\circ}, \S 2^{\circ}\right)$; instituía a área máxima para propriedade de imóveis rurais $\left(\operatorname{art.} 4^{\circ}\right)$; fixava o pagamento das indenizações com base no valor declarado para fins tributários (art. $3^{\circ}$ ) (BRASIL, 1988, p. 48).

${ }^{9}$ A abertura para apresentação de emendas pela população ao anteprojeto da Constituição representou uma novidade na dinâmica de funcionamento do processo constituinte. Segundo Rattes (2009, p. 27), as 122 emendas populares totalizaram 12.277.423 assinaturas, sendo que cada eleitor só podia subscrever, no máximo, três propostas.

${ }^{10}$ Nos aspectos ligados à propriedade e à reforma agrária, a principal frente conservadora era constituída pela União Democrática Ruralista (UDR), grupo formado por proprietários de terras rurais. A UDR, como consta no seu site próprio, é uma "entidade de classe que se destina a reunir ruralistas e tem como princípio fundamental a preservação do direito de propriedade e a manutenção da ordem e respeito às leis do País". Disponível em: <http://www.udr.org.br/historico.htm> Acesso em: 17/05/2017.
} 


\section{A PROPRIEDADE RURAL NOS DEBATES DA ASSEMBLEIA NACIONAL CONSTITUINTE}

decorrendo disso uma articulação com os parlamentares considerados de centro para possibilitar a modificação do Regimento Interno.

\subsection{A reação dos conservadores e o papel do centrão na Constituinte}

Esse movimento, que envolveu parlamentares que não tinham uma posição política definida nem como de direita, nem como de esquerda, ficou conhecido como "Centrão", e com o apoio do governo, também participante da organização do grupo, conseguiu obter mais de 280 votos para modificar o Regimento Interno ${ }^{11}$.

Cabe lembrar que é nesse contexto que surge também a expressão "buraco negro", que se refere à inclusão, pelo Centrão, no Regimento Interno da ANC, do dispositivo que possibilitava a não aprovação de um capítulo por insuficiência de votos por qualquer das partes, caso o impasse não fosse resolvido com a mediação de nova proposta do Relator ${ }^{12}$.

Silva (1989, p. 170) sintetiza a movimentação política da ANC da seguinte forma: “enquanto a Comissão de Sistematização, com forte influência de progressistas, procurava explicar o que seria a nova nação brasileira, o Centrão, conservador, procurava ser o mais genérico possível".

Assim, após a crise instalada pelo Centrão, a Comissão de Sistematização desaparece, sendo substituída pela figura individual do Relator, com as votações do texto ocorrendo em primeiro e segundo turnos, com importantes modificações, dentre as quais, destaca-se a impenhorabilidade das pequenas propriedades rurais.

Segundo Silva (1989, p. 168) foi o apoio pessoal do senador Nelson Carneiro, do PMDB/RJ que garantiu a aprovação e permanência, no texto constitucional, da impenhorabilidade das pequenas propriedades rurais ${ }^{13}$ (atual inciso XXVI do art. $5^{\circ}$ ). $\mathrm{O}$ instituto foi inserido durante as discussões da Comissão de Sistematização, por emenda, na mesma sessão que aprovou o acordo sobre o direito de propriedade.

\footnotetext{
${ }^{11}$ Segundo Rattes (2009, p. 2), deve ser creditado ao Centrão o retrocesso da modificação do Sistema de governo de parlamentarismo para presidencialismo e o mandato ampliado de cinco anos em vez de quatro para o governo de transição.

${ }^{12}$ Essa mudança aconteceu em 3 de dezembro de 1987, quando foi aprovada em Plenário. O Regimento Interno da ANC havia sido aprovado em 10 de março de 1987.

${ }^{13}$ Nesse contexto, em São Paulo e no Rio Grande do Sul já haviam sido registrados casos de gerentes de bancos articulados com compradores de terras para forçar a penhora de mutuários e em decorrência de dívidas de crédito agrícola por conta da frustração de safras ou atualização financeira em decorrência dos planos econômicos (SILVA, 1989, p. 168).
} 
Outro ponto ligado à atuação do Centrão foi a exclusão da "propriedade produtiva" da possibilidade de desapropriação para fins de Reforma Agrária, conforme será melhor detalhado.

\subsection{Desapropriação para fins de reforma agrária e o problema da produtividade}

No que concerne à possibilidade de desapropriação de propriedades produtivas, é interessante notar como, utilizando-se do Regimento Interno, os Constituintes do chamado “Centrão" conseguiram que a proposta do Relator, que havia sido aprovada com apenas quatro votos contrários, passasse a uma segunda votação, na qual acabou sendo aprovada uma emenda supressiva excluindo a "propriedade produtiva" da possibilidade de desapropriação para fins de Reforma Agrária. Vejamos:

A Emenda Coletiva $n^{\circ}$ 2.043, submetida pelo Centrão para modificar a redação de alguns artigos do Capítulo III do Título VII, Da Política Agrícola e Fundiária e da Reforma Agrária, foi votada pelo Plenário em 4 de maio de 1988, na 262 a sessão, durante o $1^{\circ}$ turno, sendo derrotada por não alcançar os 280 votos necessários.

Vale destacar que referida Emenda Coletiva trazia em sua redação o seguinte teor:

Art. 217 [...]

$\S 5^{\circ}$ São insusceptíveis de desapropriação para fins de reforma agrária, nos termos da lei:

I - os pequenos e médios imóveis rurais, desde que seu proprietário não possua outro;

II- a propriedade produtiva;

III - a parte produtiva da propriedade, limitada, neste caso, a desapropriação, ao máximo de setenta e cinco por cento da área total, se assim desejar o proprietário. (BRASIL, 1988b, p. 10261, grifo nosso).

Como não se atingiu a maioria regimental, nem para aprovação, nem para a rejeição da emenda, foi realizada nova votação em 05 de maio, a qual também não atingiu a maioria regimental.

Diante do impasse, foi celebrado um acordo entre o líder do PMDB, Mário Covas, em nome dos progressistas, e o Centrão, prevendo a rejeição conjunta da Emenda Coletiva n. 2.043 e do Projeto da Comissão de Sistematização, que seria votado em seguida (SILVA, 1989, p. 185).

No Projeto da Comissão, a exceção para desapropriação havia sido prevista no $\S 2^{\circ}$ do art. 220: "São insuscetíveis de desapropriação para fins de reforma agrária os pequenos e 


\section{A PROPRIEDADE RURAL NOS DEBATES DA ASSEMBLEIA NACIONAL CONSTITUINTE}

médios imóveis rurais, definidos em lei, desde que seus proprietários não possuam outro imóvel rural" (BRASIL, 1988b, p. 10266).

Após a terceira votação, e com a rejeição de ambas as propostas, o procedimento regimental permitia a realização de nova sessão para discutir o Capítulo III do Título VII. O Relator da Comissão apresentou novo texto ao Plenário, para evitar o "buraco negro" no capítulo da reforma agrária, o qual foi aprovado pelos parlamentares na quarta votação, realizada em 10 de maio de 1988.

Antes, porém, nessa mesma manhã, por conta da omissão do Regimento Interno, o Presidente da ANC, Ulysses Guimarães, decidiu sobre a possibilidade de Destaque de Votação em Separado ${ }^{14}$ (DVS) para os casos em que houvesse emenda supressiva a algum artigo da Proposta do Relator.

Assim, o Deputado Allysson Paulinelli, ex-ministro da agricultura do governo Geisel (1974-79), que era ligado à UDR, subscreveu o Requerimento de DVS nº 2.279 para a seguinte expressão: “cuja inobservância permitirá sua desapropriação nos termos do Art. 218”, que encerrava a redação do Parágrafo Único do Art. 219 do novo texto do Relator, abaixo transcrito:

Art. 219. São insuscetíveis de desapropriação para fins de reforma agrária:

I - a pequena e média propriedade rural, assim definida em lei, desde que seu proprietário não possua outra;

II - a propriedade produtiva.

Parágrafo único. A lei garantirá tratamento especial à propriedade produtiva e fixará normas para o cumprimento dos requisitos relativos à sua função social, cuja inobservância permitirá $a$ sua desapropriação, nos termos do artigo 218. (grifo nosso)

Sob protesto de alguns congressistas, a possibilidade do destaque foi colocada em votação e aprovada, e logo em seguida, dentro da sistemática imposta pela interpretação do Regimento, foi votada a DVS no 2.279 .

O resultado (268 votos a favor da manutenção do texto contra 253 pela sua supressão), apesar de favorável, não foi suficiente para garantir a permanência do Parágrafo Único do art. 219 em sua integralidade, já que na sistemática adotada, como exposto acima, o quórum mínimo necessário para a rejeição de um DVS era de 280 votos.

Com isso, permitiu-se que a chamada "propriedade produtiva" se tornasse insuscetível de desapropriação para fins de reforma agrária.

$\mathrm{Na}$ visão dos conservadores ruralistas, o que aconteceu foi que

${ }^{14}$ Sobre a DVS, ver arts. $8^{\circ}$ e 10 do Regimento. 
Os proprietários rurais sentiram a necessidade de se mobilizarem para conscientizar o Congresso Nacional a criar uma Legislação que assegurasse os direitos de propriedade. Na época, uma ala política de esquerda radical queria acabar com esse direito com objetivo explícito de se implantar um sistema comunista no Brasil. A reação dos ruralistas foi imediata, decidiram então fundar a União Democrática Ruralista - UDR. Foi a maior mobilização do setor já visto neste país. Com isso, conseguiu-se colocar na Constituição de 1988 a Lei que preserva os direitos de propriedade rural em terras produtivas. (UNIÃO DEMOCRÁTICA RURALISTA, [s.d.]).

Outros aspectos dessa discussão acerca da possibilidade de desapropriação de propriedades produtivas também mereceram destaque. Silva (1989, p. 198) recuperou as discussões travadas em plenário no dia da votação do Capítulo III do Título VII (29 de agosto de 1988), quando o senador Mário Covas (PMDB/SP), a partir do exemplo do trabalho escravo, explicava que nem sempre a propriedade produtiva cumpria a sua função social.

Na mesma linha seguia Nelson Jobim (PMDB/RS), que pugnava pela supressão do inciso relativo à impossibilidade de desapropriação da propriedade produtiva, pois esta já estaria isenta de desapropriação caso cumprisse sua função social. Isto, em virtude do que estava consignado no parágrafo único do art. 190 que dizia que "a lei garantirá tratamento especial à propriedade produtiva e fixará normas para o cumprimento dos requisitos relativos a sua função social".

Outros aspectos, relativos à Política Agrícola e Fundiária na ANC merecem ser destacados.

\subsection{Outras questões relacionadas à Política Agrícola e Fundiária na Constituinte}

Uma questão que aparentemente passou sem maiores discussões diz respeito ao estabelecimento de áreas mínimas para efeito de desapropriação. Silva destaca apenas um trecho do pronunciamento do deputado Luiz Freire, do PMDB/PE, em sessão extraordinária sobre a o tema, justificando as áreas mínimas da seguinte forma:

“A legislação ordinária não pode deixar de estabelecer áreas mínimas para efeito de desapropriação para fins de Reforma Agrária. Afastar-se-ia, assim, a insegurança e desconfiança dos pequenos e médios proprietários referentes ao propósito da Reforma Agrária” (SILVA, 1989, p. 117).

Por sua vez, o art. 50 do Ato das Disposições Constitucionais Transitórias (ADCT) estabeleceu prazo para a promulgação de uma lei que dispusesse sobre objetivos e instrumentos de política agrícola. Silva (1989, p. 193) ressalta que esse dispositivo é de inspiração patronal, 


\section{A PROPRIEDADE RURAL NOS DEBATES DA ASSEMBLEIA NACIONAL CONSTITUINTE}

e oculta uma antiga reivindicação do setor, de que a política de reforma agrária fosse substituída por uma política de crédito fundiário:

Art. 50. Lei agrícola a ser promulgada no prazo de um ano disporá, nos termos da Constituição, sobre os objetivos e instrumentos de política agrícola, prioridades, planejamento de safras, comercialização, abastecimento interno, mercado externo e instituição de crédito fundiário (grifo nosso).

Cabe ainda mencionar que durante os trabalhos da ANC, o Ministério Extraordinário para o Desenvolvimento e a Reforma Agrária (MIRAD), do qual à época era ministro Jáder Barbalho, chegou a editar em 21 de outubro de 1987 o Decreto Lei n ${ }^{\circ} 2.363$, tentando implementar duas exceções às desapropriações por interesse social defendidas pelo Centrão: a da Função Social e a da Propriedade Produtiva.

Referido Decreto, que foi publicado poucos dias antes da votação do Capítulo relativo à Política Agrícola, Fundiária e da Reforma Agrária da Constituição, extinguiu o INCRA, transferindo suas atribuições para o MIRAD, com exceção das inerentes à Procuradoria Geral, que foram transferidas para o Instituto Jurídico de Terras (INTER).

Monte (2013, p. 31) explica que a

extinção do INCRA, naquela oportunidade, estivera ligada a uma pretensa 'ampla reforma administrativa', anunciada pelo governo Sarney. O que se tem como verdade é que a decisão buscava livrar-se de uma autarquia incômoda, cujas ações demandadas por sua alta direção, comprometidas com a realização da reforma agrária e o atendimento dos anseios dos trabalhadores rurais, poderiam desencadear um processo irreversível de redistribuição de terras gerando inquietações nas elites rurais e impasses políticos no núcleo do governo.

Outro ponto que merece destaque diz respeito ao limite constitucional para alienação de terras públicas sem prévia autorização do Congresso Nacional. O projeto da Comissão de Sistematização previa a necessidade de autorização prévia para a concessão ou alienação de terras públicas com área superior a 500 hectares.

Em dissonância com a Constituição de 1969, que havia fixado esse limite em 3.000 hectares, depois da Emenda Coletiva 2P2040, o limite foi fixado em 2.500 hectares, a partir do novo texto apresentado pelo Relator da Comissão (Bernardo Cabral), para evitar o "buraco negro", conforme já destacado anteriormente.

É interessante notar que alguns temas ligados à política agrária, tais como a justiça agrária e o imposto territorial rural (ITR), foram tratados fora dos Capítulos I (Dos Princípios Gerais da Atividade Econômica) e III (Da Política Agrícola e Fundiária e da Reforma Agrária) do Título VII (Da Ordem Econômica e Financeira). 
Na Constituição Federal de 1969, não havia nenhum dispositivo referente ao ITR. O dispositivo que trata do ITR foi inserido e aprovado antes da votação do Capítulo III do Título VII, e manteve o imposto como de competência da União. Também ficou definido que a fixação de suas alíquotas objetivaria desestimular a manutenção das propriedades improdutivas e não incidiria sobre os pequenos imóveis rurais familiares para os proprietários que não possuíssem outro imóvel.

\section{CF/88: AVANÇO OU RETROCESSO?}

Muito se discute sobre o resultado do processo Constituinte no âmbito de ingerência das políticas ligadas à reorganização da estrutura fundiária e ao desenvolvimento rural.

Silva (1989) entende que a Constituição de 1988 acabou sendo mais retrógrada que o próprio Estatuto da Terra, editado durante o regime militar. Essa crítica também pode ser observada em Santos (apud TRECCANI, 2001, p. 148), ainda na primeira fase de votação da ANC:

A impressão que fica da leitura das normas aprovadas nessa primeira votação, é a de que o Estado tende a inviabilizar definitivamente uma reforma agrária legal de caráter massivo, rápido e generalizado, como vinham insistentemente pedindo os trabalhadores rurais. O Projeto institui, por outro lado, grandes entraves de ordem burocrática e procedimental à consumação dos atos de expropriação. Entrementes esvazia o conceito de "função social da propriedade", que outrora representava o conjunto de deveres e condições que legitimavam a continuação da propriedade privada, na medida em que basta a "produtividade" das terras que o respectivo proprietário fique isento da desapropriação, mesmo que possua vários latifúndios em distintas regiões.

Segundo Silva (1989, p. 200 e ss.), a CF/88, quando comparada com os dispositivos constitucionais outorgados pelos governos militares do período de 1964/69, bem como a Emenda Constitucional n $n^{\circ}$ 10/64 e o Estatuto da Terra, apenas elevou à proteção constitucional diversos artigos da legislação ordinária, porém recuou quando estabeleceu a necessidade do prévio pagamento de indenizações devidas por desapropriações por interesse social para fins de reforma agrária, e introduziu o bloqueio da impenhorabilidade da propriedade produtiva.

Marés (1999, p. 514) observou que

quando a Constituição foi escrita, porém, os chamados ruralistas, nome gentil dado aos latifundiários, foram construindo dificuldades no texto constitucional para que ele não pudesse ser aplicado. Como não podiam desaprovar claramente o texto cidadão, ardilosa e habilmente introduziram senões, imprecisões, exceções que, contando com a interpretação dos juízes, tribunais e do próprio poder executivo, fariam do texto letra morta, transportando a esperança 


\section{A PROPRIEDADE RURAL NOS DEBATES DA ASSEMBLEIA NACIONAL CONSTITUINTE}

anunciada na Constituição para o velho enfrentamento diário das classes dominadas, onde a lei sempre conta contra.

As conclusões de Cunha Filho (2007, p. 170) sobre os rumos da política fundiária brasileira são precisas:

A partir da Constituição de 1988, apesar de ter sido conferido status constitucional à função social da propriedade e ter sido fixado (sic) os critérios para o seu cumprimento no art. 186, o texto constitucional acabou com a possibilidade de desapropriação dos latifúndios unicamente em razão de sua extensão, tornou insuscetível de desapropriação a propriedade produtiva e fez retornar a exigência de que a indenização seja prévia.

A lei $n^{\circ} 8.629 / 93$ e a lei complementar $n^{\circ}$ 76/93 aprofundaram ainda mais o retrocesso iniciado pela Constituição de 1988, uma vez que: 1) aumentaram sobremaneira as possibilidades do (sic) Poder Judiciário impedir ou interromper as desapropriações e o consequente processo de assentamentos dos beneficiários da reforma agrária; 2) o valor da indenização passou a ser vinculado ao valor de mercado do imóvel rural; 3) a transferência do domínio passou a se dar somente após o pagamento integral da indenização, sendo o INCRA apenas imitido provisoriamente na posse do imóvel, fato que permite a condenação do INCRA ao pagamento de juros compensatórios, o que aumenta de forma considerável os custos das desapropriações.

Parece que a sociedade perdeu duas vezes. Primeiro porque os defensores das políticas distributivas de acesso à terra concentraram seus esforços em torno da bandeira da reforma agrária, deixando de lado outras ações que poderiam gerar efeito semelhante. Em segundo lugar, porque esse direcionamento criou um embate feroz com parte do setor ruralista, cuja mobilização e atuação estratégica acabou inviabilizando a utilização dos instrumentos postos à disposição para realização da reforma agrária na amplitude desejada.

\section{CONSIDERAÇÕES FINAIS}

O processo legislativo constitucional carregou consigo uma tensão sobre o papel da propriedade no desenvolvimento rural, conforme se verificou dos debates da ANC. A consequência disso é que a CF/88 não exprime claramente se o Estado deve outorgar garantias mínimas materiais no aspecto da propriedade rural como condição de realização da justiça social.

Pode-se afirmar, ainda, que a Constituição de 1988 manteve o status constitucional conferido à função social da propriedade, inviabilizando, porém, uma efetiva intervenção do Estado no processo de gestão territorial, a partir da modificação da estrutura agrária do país. 
Por outro lado, é possível concluir também que o direcionamento histórico de esforços da sociedade civil e dos movimentos sociais em torno da bandeira da reforma agrária, como mostram os debates da ANC, não surtiu o efeito desejado.

É possível inferir também que as políticas públicas implementadas a partir do direcionamento constitucional não foram capazes de modificar a estrutura fundiária do país e proporcionar efetiva melhoria das condições de vida no espaço agrário. Continuamos vivenciado a tensão entre proprietário e camponês, entre aquele que possui a terra e aquele que a cultiva.

Por isso, é preciso avançar no debate em torno do espaço rural e na compreensão das estruturas básicas sob as quais se organizam a produção e a vida rurais. Torna-se necessário pensar alternativas para o desenvolvimento rural a partir de arranjos institucionais mais eficientes, através de outros modelos de políticas públicas. 


\section{REFERÊNCIAS}

BRASIL. Assembleia Nacional Constituinte. Emendas populares. v. 258, Brasília: janeiro de 1988. Disponível em: <http://www.camara.gov.br/internet/ constituicao20anos/DocumentosAvulsos/vol-258.pdf> Acesso em: 17/05/2017.

Diário da Assembleia Nacional Constituinte. Sexta-feira, 6 de Maio de 1988b. Disponível em: <http://imagem.camara.gov.br/Imagem/d/ pdf/240anc06mai1988.pdf> Acesso em: 17/05/2017.

CALDEIRA, Cesar (org.). Separata no 5, 15 de maio de 1986. Rio de Janeiro: Centro Ecumênico de Documentação e Informação (CEDI), 1986.

COMPARATO, Fabio Konder. O regime da propriedade rural. In: CALDEIRA, Cesar (Org.). Separata $n^{0}$ 5. 15 de maio de 1986. Rio de Janeiro: Centro Ecumênico de Documentação e Informação (CEDI), 1986.

CUNHA FILHO. Sergio de Britto. A Constituição de 1988 e a diminuição do poder estatal de desapropriar imóveis rurais para fins de reforma agrária. Dissertação (Mestrado). Pontificia Universidade Católica, PUC-Rio, 2007. Rio de Janeiro: 2007. Disponível em: <http://www.maxwell.vrac.puc-rio.br> Acesso em: 17/05/2017.

DRESCH, Rafael de Freitas Valle. Fundamentos do direito privado: uma teoria da justiça e da dignidade humana. São Paulo: Atlas, 2013.

MARÉS, Carlos Frederico. Direito agrário e meio ambiente. In: LARANJEIRA, Raymundo (Coord.). Direito agrário brasileiro. São Paulo: LTr, 1999. p. 507-519.

MONTE, Francisco Clesson Dias. O INCRA e a política de assentamentos rurais: um estudo sobre processos político-administrativos de ação pública. Tese (doutorado). Rio de Janeiro: UFRRJ, Instituto de Ciências Humanas e Sociais, 2013. Disponível em: http://r1.ufrrj.br/cpda/wp-content/uploads/2013/05/https__correio2.incra_.gov_4.pdf Acesso em: 17/05/2017.

PIKETTY, Thomas. O capital no século XXI. Tradução Monica Baumgarten de Bolle. Rio de Janeiro: Intrínseca, 2014.

RATTES, Anna Maria. Um Olhar de 20 Anos In: Constituição 20 anos: Estado, democracia e participação popular: caderno de textos (Série ação parlamentar; n 393). Brasília: Câmara dos Deputados, Edições Câmara, 2009. p. 25-30.

SARLET, Ingo Wolfgang. A eficácia dos direitos fundamentais: uma teoria geral dos direitos fundamentais na perspectiva constitucional. $12 \mathrm{ed}$. rev. atual. e ampl. Porto Alegre: Livraria do Advogado Editora, 2015.

SEVERINO, Antônio Joaquim. Metodologia do trabalho científico. 23 ed. rev. e atual. São Paulo: Cortez, 2007. 
SILVA, José Gomes da. Buraco negro: a reforma agrária na Constituinte de 1987-88. Rio de Janeiro: Paz e Terra, 1989.

TRECCANI, Girolamo Domenico. Violência e grilagem: instrumentos de aquisição da propriedade da terra no Pará. Belém: UFPA-ITERPA, 2001.

UNIÃO DEMOCRÁTICA RURALISTA. Histórico. Disponível em: <http://www.udr.org.br/historico.htm> Acesso em: 17/05/2017. 